\title{
Radionuclide concentrations in some fruit juices produced and consumed in Lagos, Nigeria
}

\author{
A. E. Adeniji ${ }^{1, *}$, O. O. Alatise $^{2}$, A. C. Nwanya ${ }^{3}$ \\ ${ }^{1}$ Department of Physics and Astronomy, University of Nigeria, Nsukka \\ ${ }^{2}$ Department of Physics, Federal University of Agriculture, Abeokuta, Nigeria. \\ ${ }^{3}$ National Center for Energy Research and Development, University of Nigeria, Nsukka
}

Email address:

emmaabidec@yahoo.com (A. E. Adeniji)

\section{To cite this article:}

A. E. Adeniji, O. O. Alatise, A. C. Nwanya. Radionuclide Concentrations in Some Fruit Juices Produced and Consumed in Lagos, Nigeria, American Journal of Environmental Protection. Vol. 2, No. 2, 2013, pp. 37-41. doi: 10.11648/j.ajep.20130202.11

\begin{abstract}
A total of seven samples of bottled fruit juice produced and consumed in Nigeria were used for the study. The average concentrations of radionuclides contained in some bottled fruit juice produced and consumed in Nigeria and also exported to neighboring countries have been estimated by means of scintillation detector which is sodium Iodide activated with thallium $(\mathrm{Na}(\mathrm{Ti}))$. The radionuclides observed with reliable regularity belonged to the series - decay naturally occurring radionuclides headed by ${ }^{238} \mathrm{U}$ and ${ }^{232} \mathrm{Th}$ as well as the non- series decay type, ${ }^{40} \mathrm{~K}$. The average specific activity values obtained for ${ }^{226} \mathrm{Ra},{ }^{228} \mathrm{Ra}$ and ${ }^{40} \mathrm{~K}$, respectively, were $16.44 \pm 5.91,13.64 \pm 3.99$ and $163.21 \pm 49.00 \mathrm{~Bq} / \mathrm{kg}$. It was observed that man made radionucldes suchas ${ }^{137} \mathrm{Cs}$ and ${ }^{90} \mathrm{Sr}$ were not detected in any of the bottled fruit juices which might be due to the countermeasures applied. The activity concentrations of each of the naturally occurring radionucldes in the bottled fruit juice were much lower than those recommended by the regulatory bodies. Thus, the contribution from these radionuclides does not pose any significant radiological health problem to the consumers.
\end{abstract}

Keywords: Radionuclides, Fruit Juice, Scintillation Detector, Sodium Iodide, Thallium, Decay

\section{Introduction}

The foods that we eat and fruits we drink contribute to some extent to our internal exposure to radiation. These foods and fruits are naturally radioactive. Fruit juice consumption has become a worldwide dietary habit and, as a result, the consumption of frozen concentrated juice has increased steadily over the years. Not surprisingly, the market share of this product is now much greater than that of fresh fruit, especially in the major cities in the countries. Naturally occurring radionuclides enter the human body mainly by inhalation of radon and thoron gases and their decay products [1], by ingestion of primordial radionuclides and their progeny, ${ }^{40} \mathrm{~K}$, and the ${ }^{238} \mathrm{U}$ and ${ }^{232} \mathrm{Th}$ series [2-4]. The ingested radionuclides could be concentrated in certain parts of the body for example ${ }^{238} \mathrm{U}$ accumulated in human kidney and lungs, ${ }^{232} \mathrm{Th}$ in liver, skeleton tissue and lungs and ${ }^{40} \mathrm{~K}$ in muscles [5]. The accumulation of these radionuclides in any organ in the body will affect the health condition which may result to inducing various forms of diseases, weakening the immune system and also contributing to increase in mortality rate. Natural sources of radia- tion - a combination of cosmic and terrestric radiation represent the major part of radioactivity in the food chain. The radionuclides potassium- 40 , uranium- 235 and -238 as well as products from these decay series such as radon-222, radium-226 and thorium-232 can be dated back to the beginning of the earth. Radionuclides such as ${ }^{40} \mathrm{~K},{ }^{226} \mathrm{Ra}$ that occur naturally in soil are incorporated metabolically into plants and ultimately find their way into food and water [6]. Generally, there are two sources of environmental radionuclide, natural (mainly from the ${ }^{238} \mathrm{U},{ }^{232} \mathrm{Th}$ series) and artificial (i.e lodine-131, Strontium-90, Caesium-134, Caesium-137 etc) sources. These radionuclides can be released into the environment as a result of human activities including energy production and military operations such as nuclear weapons testing or caused by nuclear accidents (e.g 1986 Chernobyl Disaster and 2011 Fukushina Earthquake, Lagos armoury explosion, Nigeria on 27 January 2002.). These radionuclides, when accumulated over the period of time in foods and water, constitute a direct route of natural exposure to human population when they are consumed.

Plants absorb nutrients through their roots and transport them via the phloem to active portions of the plant. ${ }^{137} \mathrm{Cs}$ 
can be absorbed by plant roots from soil solution and translocated to the above-ground plant parts [7-9]. Additionally, radiocaesium uptake can be influenced by the roots distribution within the soil profile, soil type, soil water status and characteristic rate uptake of fruit species as well as by specific activity of the roots [10]. There are large differences in the degree of translocation of radionuclides to fruits of different species, depending upon physiological characteristics of the plants. The highest experimental values for radiocaesium are observed in apple, strawberry and pear, and the lowest in orange. Among the shrubs, gooseberry shows the highest translocation and blueberry the lowest [11]. Soil-to-fruit transfer is radionuclide specific. The variability in transfer factors for a given radionuclide is attributable primarily to the different properties of soils. For example, the highest transfer factors for caesium are specific to peat or light textured soils. The lowest transfer factors for strontium are specific to organic soils, such as peat, and to soils with high calcium content. The transfer of both plutonium and americium is lower in loam, organic and calcareous soils. [12].

Due to possible transfer of these radionuclides and their progeny from fruit juice to human body. It is necessary to measure the radionuclide content of fruit juice to assess potential radiation doses and, if necessary, to take action to avoid the exposure of consumers to radiation [13]. Thus, the purpose of the present work is to identify the type of and concentrations of radionuclides present in these fruit juice with a view to establishing their radiological risk. In addition to this, we aim at establishing a baseline data which can be used to evaluate possible future changes and for setting of standards for radionuclides in these types of bottled fruit juices.

\section{Materials and Methods}

A total of seven samples of food beverages produce and consume in Nigeria were used for the study. The bottled fruit juices are Chivita (pineapple juice), Tampico (citric drink), Fumman (orange and pineapple), Lacasera (apple drink), Cway (Nitric milk), Viju milk drink (apple flavour) and 5 alive (citric burst). 1 litre Marinelli's beakers for seven different fruit juice samples and one for recording the background counts, were washed, rinsed with diluted $\mathrm{H}_{2} \mathrm{SO}_{4}$ acid to prevent the samples from being contaminated, and then dried. These clean 1-liter Marinelli beakers were then filled with the bottled fruit juices of different varieties, sealed and reweighed. The weight of each sample was then recorded and samples codes were indicated on the beaker. The sealed samples were then left for minimum of twenty eight days to reach a secular equilibrium before counting commenced. At secular equilibrium, the number of atoms of each daughter product disintegrating per second is the same as the number being created by the disintegration of the parent atoms.

The gamma- counting equipment used for this work was a $7.6 \times 7.6 \mathrm{~cm}$ scintillation detector which is sodium iodide activated with thallium (Na (Ti)), (Model Bircom) encapsulated in a $5 \mathrm{~cm}$ thick lead shield. This is coupled to a set of electronics made up of pre-amplifier, main amplifier, Analog-to-Digital Converter (ADC) and a Canberra Multichannel Analyzing (MCA) computer system. Accurate energy and efficiency calibrations of the gamma-spectrometry system were made using a standard source of radionuclides present in a sample since the accuracy of all quantitative results depends on the attainable accuracy of the system's calibration [14]. Energy calibration of the detector system is performed by measuring mixed standard sources of known radionuclides with well defined energies within the energy range of interest, usually 60-2000 keV [15]. Each sample beaker was placed on the detector surface which was enclosed by a lead shield. The shield was tightly closed. The power supplied to the detector is through $\mathrm{A} / \mathrm{C}$ stabilizer. The system was preset to 36000 seconds (counting time). Each bottled fruit juice sample was counted twice in order to check the stability of counting system.

When this time (counting time) is reached the information about the radionuclides at different photo peaks were displaced, recorded and stored in the computer. The gamma spectroscopy analysis was carried out by a spectra-analysis program, SAMPO 90, which matched $\gamma$-energies at various energy levels to a library of possible isotopes. This data analysis routine subtracted a linear background distribution from the pulse- height spectra of both the sample and the background. In addition to the net background peak being subtracted from the corresponding net peak area for a particular radionuclide, the difference between net peak and net background areas, accumulation time, absolute peak efficiency, absolute $\gamma$ - ray emission probability $(\gamma$-ray intensity) and the sample volume were calculated.. The overall uncertainty in the measured concentrations was estimated from the parameters contained in the above mentioned relation, the calibration procedure, the peak area determination and the background. [16]

\section{Result and Discussion}

\section{Activity Concentration}

Table 1 and the chart (figure 1) summarized the average specific activity concentrations of the radionuclides identified with reliable regularity in all the bottled fruit juice samples analyzed by gammy spectrometry.

The results show at a glance that the activity concentrations in all the samples are strikingly low and are within the limit of low background radiation. The most important radionuclide that gives the largest part of the dose to an average person from ingestion is $40 \mathrm{~K}$, the next most important contributors are the corresponding values for the other naturally occurring radionuclides such as ${ }^{226} \mathrm{Ra}$ and ${ }^{228} \mathrm{Ra}$ isotopes of $U$ and Th being an order of magnitude lower [17].

For these two series- decay radionuclides ( i.e Uranium and Thorium series), it is well established that radium isotopes are of major concern as a source of dietary contamination and consequently of serious internal radiation to 
man [18]. In the Uranium series, most of the $\gamma$-rays are emitted during the decay of ${ }^{214} \mathrm{~Pb}$ and ${ }^{214} \mathrm{Bi}$ but latter is the principal contributor to internal dose rate as documented by
NCRP [19]. The emission energies concerned by our study are 583, 609 and $1461 \mathrm{keV}$ for the radionuclides ${ }^{232} \mathrm{Th},{ }^{238} \mathrm{U}$ and ${ }^{40} \mathrm{~K}$, respectively.

Table 1. Activity concentration of Radionuclides in some bottled fruit juices.

\begin{tabular}{|c|c|c|c|c|}
\hline \multirow{2}{*}{ Sample } & \multirow{2}{*}{ Sample type } & \multicolumn{3}{|l|}{ Radionuclides } \\
\hline & & ${ }^{226} \mathrm{Ra}$ & ${ }^{228} \mathrm{Ra}$ & ${ }^{40} \mathrm{~K}$ \\
\hline 1 & Tampico(citric drink) & $22.90 \pm 12.06$ & $18.56 \pm 4.40$ & $258.90 \pm 81.88$ \\
\hline 2 & Chivita(pineapple juice) & $19.92 \pm 7.19$ & $15.99 \pm 6.20$ & $126.89 \pm 47.99$ \\
\hline 3 & Fumman(orange and pineapple) & $17.03 \pm 4.41$ & $09.63 \pm 3.28$ & $102.78 \pm 37.61$ \\
\hline 4 & Lacasera(apple drink) & $15.94 \pm 5.31$ & $13.88 \pm 5.56$ & $178.00 \pm 59.21$ \\
\hline 5 & Cway(Nitric milk) & $11.57 \pm 3.12$ & $14.81 \pm 2.73$ & $148.88 \pm 45.80$ \\
\hline 6 & Viju milk drink(apple flavour) & $10.07 \pm 3.97$ & $07.15 \pm 2.40$ & $224.84 \pm 42.63$ \\
\hline \multirow[t]{3}{*}{7} & 5 alive(citric burst) & $17.68 \pm 5.32$ & $15.48 \pm 3.38$ & $203.17 \pm 27.82$ \\
\hline & Range & $10.07-22.90$ & $07.15-18.50$ & $102.70-258.90$ \\
\hline & Mean & $16.44 \pm 5.91$ & $13.64 \pm 3.99$ & $163.21 \pm 49.00$ \\
\hline
\end{tabular}

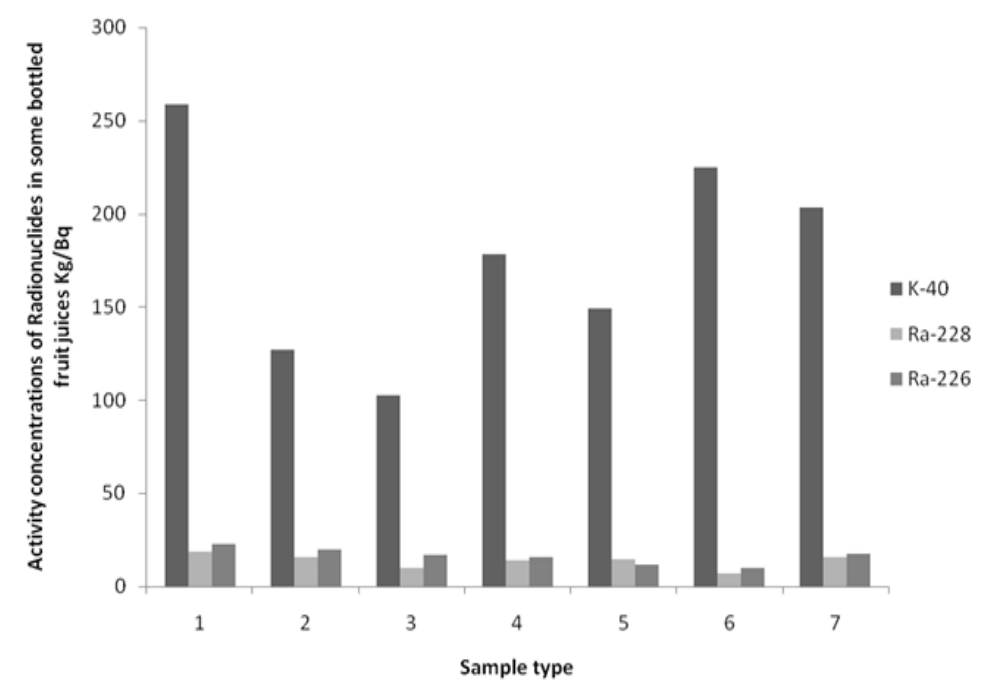

Figure 1. Chat representing the average specific activity concentrations of the radionuclides in some bottled fruit juices.

The concentration of ${ }^{40} \mathrm{~K}$ ranged from 102.70 to $258.90 \mathrm{~Bq} / \mathrm{kg}$ with a mean of $163.21 \pm 49.00 \mathrm{~Bq} / \mathrm{kg}$, the concentration of ${ }^{226} \mathrm{Ra}$ recorded a range of 10.07 to $22.90 \mathrm{~Bq} / \mathrm{kq}$ with a mean of $16.44 \pm 5.91 \mathrm{~Bq} / \mathrm{kg}$ and the concentration of ${ }^{228} \mathrm{Ra}$ ranged from 7.15 to $18.50 \mathrm{~Bq} / \mathrm{kg}$ with a mean of $13.64 \pm 3.99 \mathrm{~Bq} / \mathrm{kg}$.

${ }^{40} \mathrm{k}$ recorded the highest average total specific activity in all the bottled fruit juice samples and hence, will have the highest contribution to ingestion doses to the consumer. However, Potassium is a key element in regulating many bodily functions such as digestion, heart rate and the water content of cells. For that reason, the potassium content of the body is held constant by metabolic processes, although some variability between men and women and with age has been observed. Natural potassium contains $0.012 \%$ by weight of potassium- 40 , which is naturally radioactive. The potassium-40 content of the body is therefore also constant. The concentration of potassium (and hence ${ }^{40} \mathrm{~K}$ ) in the human body is governed by homeostatic processes, and tends to remain approximately constant [20].
This specific activity due to natural Thorium is relatively low in all the fruit juice samples. This is due to the fact that ${ }^{238} \mathrm{U}$ is very mobile than Thorium. It was observed that none of the long-live fission product (e.g. lodine-131, Strontium-90, Caesium-134, Caesium-137 etc) was detected in any of the bottled fruit juice samples judging by the initial environmental radionuclide pollution. However, the answer may lie in the fact that radiocaesium has short biological half -life of the order of 2-4 weeks [21] as well as possible countermeasures which were applied by the farmers planting these fruit trees in Nigeria. Crops have widely different uptake patterns from soil to harvest food, due to variations in their radionuclide transfer factors for the soil-plant-fruit pathway. Thus, some crops, such as corn (maize) and apples have very low concentrations of radionuclides in the final fruit, while others such as beans, have exceedingly high levels. Long storage and processing times can also reduce the activity contents of short-lived radionuclides in foodstuffs, with implications for assessments of doses from releases of radionuclides to the environment 
$[22,23]$. The delay between harvest and consumption is important for short-lived radionuclides such as ${ }^{131} \mathrm{I}$. Processing of fruits and vegetables includes surface cleansing or washing and other more vigorous or deeply penetrating measures. The efficiency of radionuclide removal through processing of plant products varies widely and can remove up to $99 \%$ of the initial activity in raw material. However, the efficiency of surface cleansing or washing of fruit and vegetables is rather low and gives a reduction in the ${ }^{137} \mathrm{Cs}$ content of up to $10-30 \%$ of the initial activity. Some more vigorous processing can be more effective. Thus, the ${ }^{137} \mathrm{Cs}$ content is reduced by $30-80 \%$ after boiling, salting, pickling, and juice and wine production [24]. The uptake of ceasium and strontium into plants can be partially blocked by using other chemicals (notably potassium and phosphorus) as fertilizer and liming by increasing calcium levels can reduce radiostrontium uptake, cultivating crops such as sugar beet or oil seed rape where the edible products are processed and contamination reduced, burying the contaminated surface of the land by deep ploughing could be an effective procedure for large farms provided that proper ploughs are available because Strontium-90 and Caesium-137 are widely distributed in near-surface soil roughly exponentically with depth [25].

\section{Conclusion and Recommendation}

This work helped in identifying and measuring the specified activity of radionuclide present in bottled fruit juices consuming in Nigeria, in order to determine their activity concentrations and asses the health impact on the general public who mighty be directly involved in the consumption of these bottled fruit juices. The investigation is also very useful in ascertaining the level of health risks that might be involved for those countries that consuming bottled fruit juices both internally and internationally.

This study also shows that the radionuclides presents differ in type and quantity in these bottled fruit juices. This might be due to the heterogeneity of the environments in which the radionuclides are deposited since it could be greatly influenced by the type of soil, water transportation and precipitation by organic metabolism or by ground water as well as other numerous factors.

The health impact assessment of this study revealed that the general public are not being subject to any radiological epidemiology until now when consuming these selected bottled fruit juices. This may be due to the relatively low concentrations of the radionuclides headed by ${ }^{238} \mathrm{U}$ and ${ }^{232} \mathrm{Th}$ as well as a single-decay type, ${ }^{40} \mathrm{k}$. The average specific activity contents of ${ }^{238} \mathrm{U},{ }^{232} \mathrm{Th}$ and ${ }^{40} \mathrm{k}$ in bottled fruit juices in this study have values which agreed with those reported in previous work by many other countries of the world [26-29]. Because of their low activity concentrations, they cannot constitute any health hazard to the general public consuming these bottled fruit juices. Hence, there is a need for regular monitoring of the consumption of selected bottled fruit juices both internally and internationally since all doses may have a commutative effect.

\section{Acknowledgements}

The authors would like to thank Dr Pascal Tchokossa from the Department of Physics, Obafemi Awolowo University, Ile Ife, Osun State, Nigeria for his assistance in setting up the NaI detector for the research work and also the interpretation of the results.

\section{References}

[1] M. A. Misdaq, H. Ezzahery, D. Elabboubi, "Determination of equivalent dose rates and committed effective doses in the respiratory system from the inhalation of radon decay products by using SSNTD and a dosimetric compartmental model”. Radiat. Prot. Dosim., 2001b, Vol. 93, pp 347-355.

[2] I. M. Fisenne, P. M. Perry, K. M. Decker, H. K. Keller, "The Daily Intake of 234,235,238U, 228,230,232Th, and 226,228Ra by New York City Residents," Health Phys, 1987, Vol. 53, pp. 357-363.

[3] K. Shiraishi, K. Tagami, Y. Muramastu, M. Yamamoto "Contributions of 18 food categories to intake of $232 \mathrm{Th}$ and 238U in Japan”. Health Phys, 2000, Vol.78, No1, pp 28-36.

[4] C. Kuwahara, K. Koyama, H. Sugiyama, "Estimation of daily Uranium ingestion by Urban residents in Japan”. J. Radioanal. Nucl. Chem., 1997, Vol. 220, pp 161.

[5] A. A. Tawalbeh, S.B. Samat, M.S. Yasir, M. Omar, "Radiological Impact Of Drinks Intakes Of Naturally Occurring Radionuclides On Adults Of Central Zone Of Malaysia". The Malaysian Journal of Analytical Sciences, 2012, Vol. 16, No 2, pp187-193.

[6] M. Eisenbud, T. Gesell "Environmental Radioactivity from Natural Industrial and Military Sources". 4th ed., Academic Press An Imprint of Elsevier, 1997.

[7] B. Delvau, N. Kruyts, E. Maes, E. Smolders, "Trace elements in the rhizosphere". In: G.R. Gobran, W.W. Wenzel, and E. Lombin, (Eds.), Fate of Radiocesium in Soil and Rhizosphere. CRC Press, Boca Raton, FL, 2000, pp. 61-91.

[8] P.J. White, M. R. Broadley, "Mechanisms of caesium uptake by plants". New Phytologist, 2000, Vol.147, pp 241-256.

[9] Y.G. Zhu, E. Smolders, "Plant uptake of radiocaesium: a review of mechanisms, regulation and application". Journal of Experimental Botany, 2000, Vol.51, pp 1635-1645.

[10] C.J. Atkinson, A.D.Webster, "The influence of the development of temperate fruit tree species on the potential for their uptake of radionuclides". Journal of Environmental Radioactivity, 2001, 52, pp 131-146.

[11] P.Kopp, W.Görlich, W.Burkart, H.J. Zehnder, "Foliar uptake of radionuclides and their distribution in the plant", Proceedings of environmental contamination following a major nuclear accident, IAEA, Vienna, 1990, Vol. 2, pp 37.

[12] F. Carini, "Radionuclides in plants bearing fruits: an overview". Journal of Environmental Radioactivity, 1999, Vol. 46, No1, pp 77- 97. 
[13] M. A Misdaq, A Mortassim. "The influence of the nature of soil and plant and pollution on the 238U, 232Th, 222Rn and $220 \mathrm{Rn}$ concentrations in various natural honey samples using nuclear track detectors: Impact on the adult consumers", PRAMANA journal of physics November, 2009, Vol. 73, No. 5, pp. 859- 879 .

[14] J.B.Olomo, M.K. Akinloye, F.A. Balogun, "Distribution of gamma-emitting natural radionuclide in soils and water around nuclear research establishments, Ile Ife, Nigeria". Nucl. Instr. Meth. Phys. Res. Sect. A Accelerators, Spectrometers, Detectors Assoc. Equipment, 1994, Vol.353, pp 553557.

[15] International Atomic Energy Agency (IAEA) "Measurement of Radionuclides in Food and the Environment". IAEA Technical Report 295. IAEA, Vienna Austria, 1989.

[16] P. Tchokossa, J.B. Olomo, O.A. Osibote, "Radioactivity in the community water supplies of Ife-Central and Ife-East local government areas of Osun State, Nigeria", Instr. Meth. Phys. Res. Sect. A, 1999, Vol.422, pp 784-789.

[17] G.J.Ham, L.W. Ewers, B.T. Wilkins, "Variations in Concentrations of Naturally Occuring Radionuclides in Foodstuffs". NRPB-M892, Oxon, 1998, pp 49.

[18] United Nations, Report of Scientific Committee on the effects of radiation, Seventeenth Session, 1962, No 16.

[19] National Council on Radiation Protection and Measurements, "Environmental radiation measurements", NCRP Report No. 50, NCRP Bethesda, MD.

[20] P.A. Colgan , C. Organo, C. Hone, D. Fenton, "Radiation doses received by the Irish population", Radiological protection institute of Ireland, 2008.

[21] O.A. Osibote, J.B. Olomo, P. Tchokossa, F.A. Balogun Radioactivity in milk consumed in Nigeria 10 years after Chernobyl reactor accident, Instr. Meth. Phys. Res. Sect. A,
1999, Vol.422, pp 778-783.

[22] N. GREEN, "The effect of storage and processing on radionuclide content of fruit, Journal of Environmental Radioactivity", 2001, Vol.52, pp 281-290.

[23] Rodos: Decision support system for off-site nuclear emergency management in Europe (EHRHARDT, J., WEIS, A., Eds.) Report EUR 19144, ISBN No.92-828-9773-7, 2000, pp 259.

[24] V. Kashparov, S. Conney, S. Uchida, S. Fesenko, V. Krasnov, "FOOD PROCESSING. A review of available data, Quantification of Radionuclide Transfer in Terrestrial and Freshwater Environments for Radiological Assessments", IAEATECDOC-1616, Vienna, 2009, pp 577-597.

[25] J.I.Richards, R.J. Hance "Agricultural countermeasures", IAEA Bulletin (IAEA), 0020-6067, 1996, Vol. 38, No.3, pp $38-43$.

[26] U.S. Food and Drug Administration, "FDA Total Diet Study" (INTERNET): www.cfsan.fda.gov/ lrd/pestadd.html,1999.

[27] Codex Guideline, Codex Alimentarius Commission. Contaminants: Guideline Levels for Radionuclides in Food following Accidental Nuclear Contamination for Use in International Trade. Suppleiuentl to Codex Aliinentarius Volume XVII, 1st ed. Rome: Joint FAO/WHO Food Standards Programme, 1989.

[28] H.D. Belitz, W. Grosch, P. Schieberle, Food Chemistry 4th revised and extended ed., 2009, XLIV, 1070, pp. 481 illus. With 923

[29] H. Velasco, A.S. Cid, R.M. Anjos, C.B. Zamboni, M. Rizzotto, D.L. Valladares, J. Juri Ayub, "Variability of 137Cs and $40 \mathrm{~K}$ soil-to-fruit transfer factor in tropical lemon trees during the fruit development period", Journal of Environmental Radioactivity, 2012, Vol.104, , pp 64-70. 